\title{
PUBLIC DECISION-MAKING \\ PROCESSES AND ASYMMETRY OF INFORMATION
}




\title{
PUBLIC DECISION-MAKING PROCESSES AND ASYMMETRY OF INFORMATION
}

\author{
edited by
}

Massimo Marrelli

University of Naples, Italy

and

Giacomo Pignataro

University of Catania, Italy 


\section{Library of Congress Cataloging-in-Publication Data}

Marelli, M.

Public decision-making processes and asymmetry of information / edited by Massimo Marrelli and Giacomo Pignataro.

p. $\mathrm{cm}$.

Includes bibliographical references and index.

ISBN 978-1-4613-5626-4 ISBN 978-1-4615-1583-8 (eBook)

DOI 10.1007/978-1-4615-1583-8

1. Economic policy--Decision making. 2. Information theory in economics. 3. Pressure groups. 4. Trade regulations. I. Pignataro, Giacomo. II. Title.

HD87 .P825 2001

338.9'001'156--dc21

00-048689

Copyright $@ 2001$ Springer Science+Business Media New York

Originally published by Kluwer Academic Publishers in 2001

Softcover reprint of the hardcover 1st edition 2001

All rights reserved. No part of this publication may be reproduced, stored in a retrieval system or transmitted in any form or by any means, mechanical, photocopying, recording, or otherwise, without the prior written permission of the publisher, Springer Science +Business Media, LLC.

Printed on acid-free paper. 


\section{Contents}

Preface...................................................................

Massimo Marrelli and Giacomo Pignataro

Acknowledgements..................................................xii

Contributors...........................................................ii

Introduction

The Economics of Information and Public Policy.................1 Jean-Jacques Laffont

\section{PART 1 : THEORY}

1. Industrial Policy, Optimal Majorities and How These Can Prevent Capture................................17 Massimo Marrelli and Francesca Stroffolini

2. On the Role of Lobbies in Policy Making......................37 Isidoro Mazza

3. Delegated Control of Incentives in Regulated Industries.........67 Fabrizia Lapecorella

4. Firms, Unions and Regulators...............................89 Giacomo Pignataro

\section{PART 2 : APPLICATIONS}

5. Implementation Practices In Regulation: An Analysis of the UK Experience. Michael Waterson and Maria Vagliasindi 
6. Public Procurement In The EU..............................147 Ilde Rizzo

7. Agency and Health Care..................................... 165 Andrew Jones and Roberto Zanola

8. Incentive Failure and the Market for Information Goods.........189 Michele Trimarchi

Index. 


\section{Preface}

The problems arising from the existence of asymmetric information in public decision making have been widely explored by economists. Most of the traditional analysis of public sector activities has been reviewed to take account of the possible distortions arising from an asymmetric distribution of relevant information among the actors of the public decision-making process. A normative approach has been developed to design incentive schemes which tackle adverse selection and moral hazard problems within public organisations: our understanding of these problems is now much better, and some of the mechanisms designed have had important practical implications. While this analysis is still under way in many fields of public economics, as the papers by Jones and Zanola, and Trimarchi witness, a debate is ongoing on the possible theoretical limitations of this approach and on its actual relevance for public sector activities. This book encompasses different contributions to these issues, on both theoretical and practical areas, which were firstly presented at a conference in Catania.

The innermost problem in the current discussion arises from the fact that this normative analysis is firmly rooted in the complete contracting framework, with the consequence that, despite the analytical complexities of most models, their results rely on very simplified assumptions. Most complexities of the organisation of public sector, and more generally, of writing "contracts", are therefore swept away. Once the need for an incomplete contracting approach is recognised, the question becomes how to relax some of the assumptions characterising the complete contracting framework, without getting ad hoc results. This general theme is dealt with in the Introduction to this book, written by Jean Jacques Laffont, which sets the general grid to interpret the position of its papers in this debate. The 
starting point of Laffont's analysis is the set of inherent assumptions of the complete contracting paradigm. The relaxation of some of these assumption may contribute to focus on observed characteristics of public decisionmaking processes like: existence of constraints on commitment, favouritism, collusion in multi-agent structures, multiprincipal governing structures, incompleteness of constitutional control. He therefore recalls some contributions that can be organised along these different strands, looking at four basic policy questions, regulation of natural monopolies, procurement and auctions, provision of public goods, and economics of the environment. In his partial coverage of the incomplete contracting world, Laffont stresses the difficulties and the risk of a line of research which derives implications that may look ad hoc. In Laffont's words, "a useful guide but no panacea is to take as given the implications which are embodied in some realistic institutions (such as multiprincipal structure) rather than specifying too directly which variables are supposedly non contractible as the incomplete contract approach relying on non verifiability assumptions has been doing".

The four papers in Part 1 of the book are devoted to develop the analysis of some of the theoretical issues mentioned in the Introduction. The first two papers deal with one of the features characterising incomplete contracting, that is the multiprincipal nature of government and the complex nature of the political system. In their paper, Marrelli and Stroffolini, analyse how constitutional rules can be devised to reduce the inefficiencies of the political system due to the impossibility of discriminate consumers/voters through taxes. If the politician/regulator is not a benevolent one, do these inefficiencies inevitably lead to a retreat of public sector from intervention in the economy? Focusing on the case of regulation of firms, they study how the requirement of qualified majorities for granting discretionary power of regulation will reduce the expected welfare loss due to political inefficiency. They show that the introduction of qualified majorities can be seen as a constitutional devise to reduce the stake of capture and can also reduce the distortions caused by collusion between the regulatory agency and the firm.

Another important, but often neglected, issue concerns the characteristics of lobbying in a multistage organisation of policy-making. In principle, when the policy making process results from the interaction of different agents with some degree of authority, several opportunities for lobbying exist. Therefore, the overall influence of an interest group on the decision making process depends on the relative influence of that group at each tier of decision and on the hierarchical relationship linking those decisional levels. In his paper, Mazza presents some recent models of multi-tiered lobbying and highlights the novelties conveyed by this approach with respect to the traditional models of interest groups and regulatory capture. First, it is shown that interest groups play an important role in shaping the horizontal and 
vertical relationships within organisations. Second, the multi-tier approach to lobbying indicates that legislatorial oversight (delegation) can be endogenously induced by the influencing activities of lobbies. Third, competition for rents among interest groups extends across stages: a group with uneasy access to one stage of the organisation may prefer to shift lobbying investments to another, more favourable, stage.

The complex nature of public decision-making processes relies not only on its multiprincipal features, but also on the existence of multi-agent structures and in the consequent possibility of collusion. The remaining two papers of Part 1 deal with this problem. Lapecorella studies the incentive problem faced by a regulator who controls only one of two privately informed firms belonging to a monopolistic industry and relies on this firm for provision of correct incentives to the other. This issue is particularly relevant for those multi-product monopolistic industries, in which different firms are organised as hierarchies with one firm controlling the activity of the others, and has important policy implications. The paper presents the regulator's problem of designing effective incentives for the firm that is directly controlled, and the form of the optimal mechanism that prevents this firm from using strategically its private information as well as its contracting opportunities is derived. This incentive scheme is then compared with that designed to control each firm directly.

The multi-agent perspective is relevant not only to analyse those processes, which involve the control of different agent, but also when the internal organisation of each agent is considered. The theory of regulation has usually regarded firms as "black boxes", identifying them with their managers. In his paper, Pignataro looks at the existence of a workers' union within a firm, regulated in its output market, and considers the case of wage bargaining. The basic questions addressed in the paper are connected with the effects of regulation on wage bargaining and with the way the agreement between the firm and the union interferes with the firm's behaviour in the regulatory relationship. First, a specific control problem for the regulator is highlighted: even if the regulator is able to restrain the firm's monopoly power completely, union can extract other rents. Second, the existence of a union is a problem for the regulator for two reasons: it captures a share of the firm's informational rents and it also interferes with the strategic behaviour of the firm with respect to the regulatory scheme.

The complete contracting framework of the normative treatment of public decision-making processes with asymmetry of information raises not only some doubts on theoretical grounds but also on the practical implementability of its theoretical results. Part 2 of the book is therefore devoted to discuss the applications of the theory to different public sector activities. The first paper in the second part, by Waterson and Vagliasindi, is 
about the UK experience in the regulation of firms. They contrast the analytical sophistication in the design of regulatory schemes in theory, with the creation of ad hoc schemes in practice. Whilst the "simplicity requirement" explains the use of ad hoc frameworks, one can also note the dangers of the often observed absence of a clear conceptual base. This leads the authors to consider the main theoretical issues and the problems in their implementation. They first describe price regulation as practised in the UK, focusing on changes in the light of experience and interpretation in terms of simple models. Then they cover the structural issues in more details, including matters concerning the identification of natural monopoly and competitive issues. Finally, they move to some less-often aired questions of the nature of procedure and of type of agency in regulation.

Price regulation of firms, however, is not the only field for which theory claims its relevance: procurement is undoubtedly another one. In her paper, Rizzo reviews the relevance of most theoretical models on procurement and their recommendations on the importance of competition, in the light of the European Union experience. A widely debated issue is that, notwithstanding the extensive European legislation to open-up public markets, such an effort has not been successful. A common feature of EU member states' purchasing policies still seems to be that of favouring domestic suppliers. Theory and practice are compared in the paper, to argue that too much emphasis is put on competition, in theory, while, in practice, its role seems to be more controversial. The main argument emerging from the analysis is that heavy regulation in procurement, aimed at ensuring competition anyway, might not necessarily be effective in a domestic as well as European context.

As Laffont writes in the introduction to this book, "a systematic analysis of policy issues from [this] normative point of view which takes into account the decentralisation of information and the strategic behaviour of economic agents is under way and not quite achieved yet, even in the simplest frameworks, in areas such as health economics or environmental economics". We could also add cultural economics. The last two papers in Part 2 present the normative analysis of public sector activities in the area of health and cultural goods. Jones and Zanola survey different applications of agency models to health care provision. Possible agency relationships are identified and analysed, involving several economic actors: 1) the state, which encompasses politicians and administrators; 2) the general public in their role as both citizens and patients; 3 ) providers of insurance; purchasing agencies, such as GP fund holders and DHA in the UK; providers of health services. The introduction of third party payers, whether they be public or private insurers, brings about an agency relationship between insurers and insurees; consumers may not reveal their risk status and they do not have an incentive to minimise medical costs. In most systems the purchasing of 
health care is in the hands of third parties such as private insurers, sickness funds or DHA and GP fund holders. Here there is an agency problem when the government, as regulator, attempts to ensure that purchasers behave in the public interest. Another set of agency relationships involves the third party payer or purchaser as principal and the providers as agents. Agency relationships also occur within the internal organisation of hospitals and between government and citizens.

The paper by Trimarchi deals with the interaction between the public and the private sectors in financing producers selling goods with an informational content like education and the arts. Generally produced by non-profit institutions, such goods are characterised by different components, which often entail a trade-off. The non-profit institution producing information goods operates as the common agent of two principals, a public agency or department and a private firm, both uninformed about the agent's true type. If the principals do not act cooperatively, the agent is induced to misreport his own type and incentives fail. Principals find themselves in a dilemma, since each of them prefers the other to bear the wider proportion of the financial burden while he expects the agent to produce goods with a prevalence of his preferred characteristic. A solution is proposed in order to overcome adverse selection and it consists in principals separating the form of their support, with the public sector giving in-kind subsidies and the private sector giving monetary contributions to the non-profit.

The presentation of the papers in Catania was followed by a very lively discussion. Even if it is not possible to present this discussion within the boundaries of a book, the authors agreed to revise their papers in the light of the comments received. 


\section{Acknowledgements}

The editors wish to acknowledge with gratitude the contributions from the Italian Ministry for University and Scientific Research $40 \%$ for the research project "Asymmetries of Information and Public Decision-Making Processes", and from the Italian National Council of Research (grant No. AI95.00174.10). 


\section{Contributors}

Andrew Jones: Professor of Economics, University of York.

Jean-Jacques Laffont: Professor of Economics, Gremaq and IDEI, Toulouse.

Fabrizia Lapecorella: Professor of Public Finance, University of Bari.

Massimo Marrelli: Professor of Public Finance, University of Napoli "Federico II".

Isidoro Mazza: Research Fellow in Public Finance, University of Catania.

Giacomo Pignataro: Professor of Public Finance, University of Catania.

Ilde Rizzo: Professor of Public Finance, University of Catania.

Francesca Stroffolini: Professor of Public Finance, University of Napoli "Federico II".

Michele Trimarchi: Professor of Public Finance, University of Catanzaro.

Maria Vagliasindi: European Bank for Reconstruction and Development, Chief Economist's Office.

Michael Waterson: Professor of Economics, University of Warwick.

Roberto Zanola: Research Fellow in Public Finance, University of Torino. 